\title{
MÉTODOS PARA A SUPERAÇÃO DA DORMÊNCIA EM SEMENTES DE SUCUPIRA-PRETÁ (Bowdichia virgilioides KUNTH.)
}

\author{
Methods for dormancy overcoming of black sucupira (Bowdichia virgilioides Kunth.) seeds
}

\author{
Keline Sousa Albuquerque ${ }^{1}$, Renato Mendes Guimarães², Ísis Fernanda de Almeida ${ }^{3}$, \\ Aline da Consolação Sampaio Clemente ${ }^{3}$
}

\begin{abstract}
RESUMO
Neste estudo foram avaliados diferentes métodos para a superação da dormência em sementes de sucupira-preta. O experimento foi realizado inteiramente ao acaso em esquema fatorial 3 x 7, correspondendo a três lotes de sementes e sete tratamentos, com 4 repetições de 25 sementes. Foram utilizados ácido sulfúrico por 4,8 e 12 minutos, água a $80^{\circ} \mathrm{C}$ por 5 e 10 minutos, escarificação mecânica, mantendo-se uma testemunha. Foi observado que a espécie possui dormência tegumentar e que todos os tratamentos utilizados permitiram a entrada de água nas sementes. Contudo, alguns métodos estudados, como a água a $80^{\circ} \mathrm{C}$ por 10 minutos, resultou em um elevado número de sementes mortas. O método mais eficiente para a superação da dormência de sementes de sucupira-preta é a imersão em ácido sulfúrico, por 4, 8 ou 12 minutos, beneficiando a porcentagem e a velocidade de germinação.
\end{abstract}

Termos para indexação: Germinação, escarificação, impermeabilidade do tegumento.

\begin{abstract}
This study evaluated diferent methods to overcome dormancy of black sucupira seeds. The experiment was installed in a fully randomized design composed by a factorial scheme $3 \times 7$, correspoding to three lots of seeds and seven treatments, with 4 replicates of 25 seeds. Sulfuric acid for 4,8 and 12 minutes, water at $80^{\circ} \mathrm{C}$ for 5 and 10 minutes, sandpaper treatments were compared to the control. It was observed that this species has tegument dormancy and all treatments allowed seed imbibition. However in some of the methods used, such as like water at $80^{\circ} \mathrm{C}$ for 10 minutes, occurred a high number of dead seeds. The most suitable method for dormancy overcoming of black sucupira seeds was the imersion in sulfuric acid for 4, 8 and 12 minutes, that showed higher percentage and speed of germination.
\end{abstract}

Index terms: Germination, scarification, tegument impermeablility.

(Recebido em 28 de abril de 2006 e aprovado em 17 de novembro de 2006)

\section{INTRODUÇÃo}

Em espécies florestais nativas é comum a presença de sementes que, mesmo viáveis, não germinam, embora as condições ambientais estejam aparentemente favoráveis. Estas sementes são consideradas dormentes e podem necessitar tratamento especial para germinar. Para Bewley \& Black (1994), a dormência é um fenômeno intrínseco da semente, funcionando como mecanismo natural de resistência a fatores adversos do meio, podendo manifestar-se de três formas: dormência imposta pelo tegumento, dormência embrionária e dormência devido ao desequilíbrio entre substâncias promotoras e inibidoras da germinação.

A impermeabilidade do tegumento está associada a diversas espécies botânicas, sendo mais freqüentes nas
Fabaceae (CARVALHO \& NAKAGAWA, 2000). Espécies que produzem sementes duras representam um sério problema para os viveiristas, pois, o tegumento impermeável restringe a entrada de água e oxigênio, oferecendo resistência física ao crescimento do embrião, o que retarda a germinação, sendo prejudicial à produção de mudas (MOUSSA et al., 1998).

A impermeabilidade do tegumento pode ser superada por meio da escarificação, termo que se refere a qualquer tratamento que resulte na ruptura ou no enfraquecimento do tegumento, permitindo a passagem de água e dando início ao processo germinativo (MAYER \& POLJAKOFF-MAYBER, 1989). Entre os métodos utilizados com sucesso para a superação da dormência de espécies florestais destacam-se a escarificação química,

\footnotetext{
'Doutoranda em Agronomia/Fitotecnia - Departamento de Agricultura/DAG - Universidade Federal de Lavras/UFLA - Lavras, MG - Cx. P. 3037 37200-000 - Lavras, MG - kelinealbuquerque@yahoo.com.br

${ }^{2}$ Doutor, Professor Adjunto - Departamento de Agricultura/DAG - Universidade Federal de Lavras/UFLA - Lavras, MG - Cx. P. 3037 - $37200-000$ Lavras, MG - renatomg@ufla.br

${ }^{3}$ Graduandas em Agronomia - Departamento de Agricultura/DAG - Universidade Federal de Lavras/UFLA - Lavras, MG - Cx. P. 3037 - $37200-000$ -

Lavras, MG - isisagro@yahoo.com.br; alineagrolavras@gmail.com
} 
mecânica e a imersão em água quente. A aplicação e a eficiência desses tratamentos dependem da intensidade da dormência, bastante variável entre espécies, procedências e anos de coleta.

O uso do ácido sulfúrico é comum para a quebra da dormência tegumentar, no entanto a sua eficiência está relacionada com o tempo de exposição ao ácido e à espécie. Para sementes de Dimorphandra mollis Benth., a dormência foi superada com a imersão no ácido sulfúrico por 45 a 90 minutos (HERMANSEN et al., 2000). Já para sementes de Ochroma lagopus Sw. a imersão no ácido sulfúrico por 1 minuto foi suficiente para proporcionar alta germinação (BARBOSA et al., 2004).

A escarificação mecânica constitui-se em um método simples e de baixo custo, sendo indicada como o método mais eficiente para a promoção da germinação em sementes de Caesalpinea ferrea Mart. ex Tul., Cassia grandis L., Samanea saman Merrill (LOPES et al., 1998), e Cupania vernalis Camb. (LIMA JÚNIOR, 2004). Entretanto, a escarificação excessiva pode causar danos ao tegumento e diminuir a germinação (MCDONALD \& COPELAND, 1997).

A água quente é outro método utilizado na quebra da dormência, sendo eficiente em sementes de Acacia mearnsii Wild. (MARTINS-ORDER et al., 1999) e Peltophorum dubium Spreng (OLIVEIRA, 2000) e Leucaena leucocephala (Lam.) Wit. (TELES et al., 2000).

Bowdichia virgilioides, conhecida vulgarmente com sucupira-preta é uma espécie arbórea pertencente à família Fabaceae com ampla dispersão pelo Brasil. É considerada uma planta pioneira e adaptada a terrenos secos e pobres (BRANDÃO \& FERREIRA, 1991; LORENZI, 1992). Sua madeira, por ser de alta densidade e longa durabilidade natural, é empregada na construção civil e na fabricação de móveis. É bastante utilizada em programas de reflorestamento e na recuperação de áreas degradadas de preservação permanente (LORENZI, 1992).

Apesar da sua importância econômica, a sucupirapreta possui limitações quanto ao processo de formação de mudas devido à ocorrência de dormência tegumentar, dificultando a germinação das sementes, que ocorre de forma lenta e em baixa porcentagem. Faz-se necessária, portanto, a utilização de métodos de superação de dormência para favorecer a germinação das sementes dessa espécie.

Diante do exposto, neste trabalho foi avaliada a eficiência de diferentes métodos para a superação da dormência em sementes de sucupira-preta.

\section{MATERIAL E MÉTODOS}

O experimento foi conduzido no Laboratório de Análise de Sementes do Departamento de Agricultura, da Universidade Federal de Lavras, Lavras, MG.

Foram utilizados três lotes de sementes de sucupirapreta de diferentes procedências: o lote A, coletado no município de Crato, CE, no ano de 2001; o lote B, de Boa Vista, RR, coletado em 2003 e o lote C coletado no Norte de Minas Gerais, em 2003. As sementes de cada lote foram armazenadas em sacos plásticos, sendo as do lote $\mathrm{A}$ mantidas em temperatura ambiente e as do lotes B e C mantidas em câmara fria com controle de temperatura e umidade $\left(10^{\circ} \mathrm{C}\right.$ com $45-50 \%$ UR)

Inicialmente foi determinado o grau de umidade das sementes, utilizando o método da estufa a $105^{\circ} \mathrm{C} \pm 3^{\circ} \mathrm{C}$ por 24 horas (BRASIL, 1992). Logo após as sementes foram submetidas aos seguintes tratamentos pré-germinativos: a) escarificação química com ácido sulfúrico $\left(\mathrm{H}_{2} \mathrm{SO}_{4}\right)$ concentrado por 4,8 e 12 minutos, com posterior neutralização com carbonato de cálcio $\left(\mathrm{CACO}_{3}\right)$ a $2 \%$, durante 3 minutos; b) água a $80^{\circ} \mathrm{C}$, por 5 e 10 minutos; c) escarificação mecânica com lixa (n. 120) na região oposta ao eixo embrionário, $\mathrm{d}$ ) testemunha (sem tratamento).

Após a aplicação dos tratamentos, as sementes foram desinfetadas com hipoclorito de sódio $(\mathrm{NaClO})$ a $2 \%$, por 2 minutos e, em seguida, submetidas ao teste de germinação,utilizando-se 4 repetições de 25 sementes semeadas em caixas plásticas tipo gerbox, sobre papel mataborrão, umedecido com água destilada equivalente a 2,5 vezes o peso do papel, que foram mantidas em BOD, a $30^{\circ} \mathrm{C}$, sob luz constante.

As contagens foram realizadas diariamente, por 30 dias, computando-se o número de sementes embebidas e de germinadas. A avaliação de sementes embebidas foi realizada de forma visual. Foram consideradas germinadas as sementes que apresentavam comprimento radicular maior do que $2 \mathrm{~mm}$. Após 30 dias da semeadura avaliou-se a porcentagem de germinação (BRASIL, 1992) e o índice de velocidade de germinação (MAGUIRRE, 1962).

$O$ delineamento experimental utilizado foi o inteiramente casualizado em esquema fatorial $3 \times 7$ (três lotes de sementes e sete tratamentos de superação de dormência). Os dados de germinação foram transformados em arcsen"x/100 e o índice de velocidade de germinação em "X+0,5 (BANZATTO \& KRONKA, 1995) e submetidos à análise de variância pelo programa estatístico SISVAR (FERREIRA, 2003). A comparação das médias foi realizada pelo teste de Tukey, a $5 \%$ de probabilidade. 


\section{RESULTADOS E DISCUSSÃO}

O grau de umidade das sementes dos diferentes lotes de sucupira-preta encontrava-se em torno de $9 \%$, por ocasião da instalação do experimento.

Pelos resultados da análise de variância da porcentagem de germinação e índice de velocidade de germinação, houve diferença significativa apenas entre os lotes e os tratamentos para quebra da dormência; não houve interação dos fatores (Tabela 1).

Tabela 1 - Resumo da análise de variância para porcentagem de germinação e índice de velocidade germinação (IVG) obtidos para três lotes de sementes de sucupira-preta submetidos a diferentes tratamentos de superação da dormência. UFLA, Lavras, MG, 2006.

\begin{tabular}{|c|c|c|c|}
\hline \multicolumn{4}{|c|}{ QM } \\
\hline $\mathrm{FV}$ & GL & Germinação & IVG \\
\hline Lote & 2 & $3340,33465^{*}$ & $1,207845^{*}$ \\
\hline Tratamento & 6 & $170,130966 *$ & $0,147041 *$ \\
\hline Lote $*$ tratamento & 12 & $134,738699^{\mathrm{NS}}$ & $0,034084^{\mathrm{NS}}$ \\
\hline Erro & 63 & 94,211288 & 0,020316 \\
\hline $\mathrm{CV}(\%)$ & & 29,76 & 13,21 \\
\hline
\end{tabular}

Pelos resultados obtidos no teste de germinação, observa-se que todos os métodos pré-germinativos para a superação da dormência das sementes de sucupira-preta foram eficientes para favorecer a embebição e o conseqüente amolecimento do tegumento (Figura 1). Entretanto, destacaram-se o ácido sulfúrico, nos tempos de 8 e 12 minutos e a escarificação mecânica, os quais resultaram em $100 \%$ de sementes embebidas, independente do lote, ao contrário da testemunha, em que a porcentagem de sementes embebidas foi de $36 \%$ para o lote B, $54 \%$ para o lote $\mathrm{C}$ e $65 \%$ para o lote $\mathrm{A}$.

De acordo com esses resultados, verifica-se a necessidade de utilização de tratamentos pré-germinativos para o desencadeamento da germinação em sementes de sucupira-preta. Resultado semelhante para essa espécie foi constatado por Andrade et al. (1997) que obtiveram valores de germinação em torno de $2 \%$ sem nenhum tipo de tratamento.

$\mathrm{O}$ tratamento que resultou em maior porcentagem de germinação foi a imersão das sementes em ácido sulfúrico concentrado nos tempos de 4, 8 e 12 minutos, diferindo dos demais tratamentos (Tabela 2). Diversos autores constataram a eficácia do ácido sulfúrico na quebra da dormência e promoção da germinação de sementes de sucupira-preta. Porém, esta eficiência foi obtida utilizandose diferentes tempos de imersão das sementes em ácido sulfúrico. Smiderle \& Souza (2003), estudando sementes de sucupira-preta, obtiveram $90 \%$ de germinação com 5 minutos de imersão; já Sampaio et al. (2001) observaram, para a mesma espécie, os melhores resultados entre 8 e 11 minutos, atingindo $80 \%$ de germinação.

A diferença observada entre os lotes pode ter ocorrido devido a variações genético-ambientais entre os

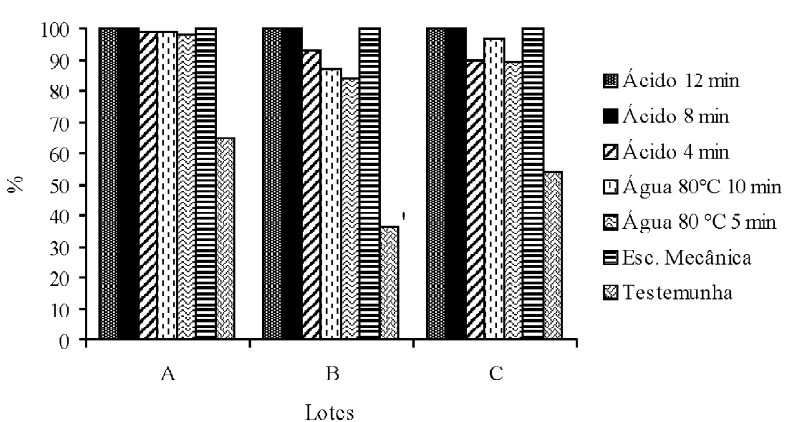

Figura 1 - Porcentagem média de sementes embebidas obtidas no teste de germinação para três lotes de sementes de sucupira-preta submetidos a diferentes tratamentos de superação da dormência. UFLA, Lavras, MG, 2006.

Tabela 2 - Germinação (\%) e índice de velocidade de germinação (IVG) de sementes de sucupira-preta submetidas a diferentes tratamentos para a superação da dormência. UFLA, Lavras, MG, 2006.

\begin{tabular}{lcc}
\hline \multicolumn{1}{c}{ Tratamentos } & \% Germinação & IVG \\
\hline Ácido $12 \mathrm{~min}$ & $75 \mathrm{~A}$ & $1,37 \mathrm{~A}$ \\
Ácido $8 \mathrm{~min}$ & $77 \mathrm{~A}$ & $1,40 \mathrm{~A}$ \\
Ácido $4 \mathrm{~min}$ & $71 \mathrm{AB}$ & $1,30 \mathrm{AB}$ \\
Água $80^{\circ} \mathrm{C} 10 \mathrm{~min}$ & $63 \mathrm{BC}$ & $0,69 \mathrm{BC}$ \\
Água $80^{\circ} \mathrm{C} 5 \mathrm{~min}$ & $59 \mathrm{C}$ & $0,65 \mathrm{C}$ \\
Escarificação & $66 \mathrm{~B}$ & $0,89 \mathrm{~B}$ \\
mecânica & & \\
Testemunha & $11 \mathrm{D}$ & $0,32 \mathrm{C}$ \\
\hline
\end{tabular}

Médias seguidas pela mesma letra na coluna não diferem entre si, a 5\% de probabilidade, pelo teste de Tukey. 
lotes utilizados. Alguns autores relataram que espécies com ampla distribuição geográfica podem responder diferentemente aos tratamentos utilizados, devido aos efeitos de adaptação e à origem (ALLEN \& MEYER, 1998; SCHATRAL \& FOX, 1994).

A escarificação mecânica também foi eficiente para a quebra da dormência; porém, a avaliação do teste de germinação das sementes foi dificultada, uma vez que os tegumentos permaneceram presos aos cotilédones das plântulas, dificultando a observação da protrusão da raiz primária. Além disso, favoreceu um maior desenvolvimento da parte aérea em detrimento da raiz, que atrofiava, já que a mesma não tinha "força" para romper o tegumento, aumentando o número de plântulas anormais. Resultados similares foram observados por Oliveira (2000) em sementes de Peltophorum dubium, sendo necessária a remoção dos tegumentos para que a avaliação pudesse ser realizada. De acordo com Burg et al. (1994), o desprendimento dos cotilédones é um importante fator no desenvolvimento das plântulas normais. Se os cotilédones permanecem dentro dos tegumentos, os mesmos tornam-se sujeitos a vários tipos de danos.

Analisando-se os resultados de velocidade de germinação (Tabela 2) observa-se que os melhores resultados também foram para os tratamentos utilizando ácido sulfúrico, principalmente nos tempos de 4, 8 e 12 minutos. De forma geral, houve uma tendência dos maiores valores de porcentagem de germinação estarem associados às maiores médias de velocidades de germinação. Este mesmo comportamento foi observado por Andrade et al. (1997) e Sampaio et al. (2001), para sementes de sucupirapreta, indicando a existência de uma relação direta entre os dois processos.

Na Figura 2, observa-se a porcentagem de sementes mortas verificada no teste de germinação, para cada tratamento pré-germinativo.

No tratamento utilizando água a $80^{\circ} \mathrm{C}$ foi observada menor porcentagem e velocidade de germinação (Tabela 2), quando comparadas aos demais métodos, além de gerar o maior número de sementes mortas dentre os tratamentos utilizados (Figura 2). Provavelmente, a alta temperatura empregada afetou os tecidos do embrião, causando sua morte. Comportamento semelhante foi observado por Alves et al. (2000) com redução drástica na germinação de sementes de Bauhinia monandra Britt., com água a $85^{\circ} \mathrm{C}$.

$\mathrm{Na}$ Tabela 3, encontram-se os dados referentes à porcentagem e ao índice de velocidade de germinação para as sementes dos três lotes de sucupira-preta submetidos aos tratamentos para a superação da dormência.

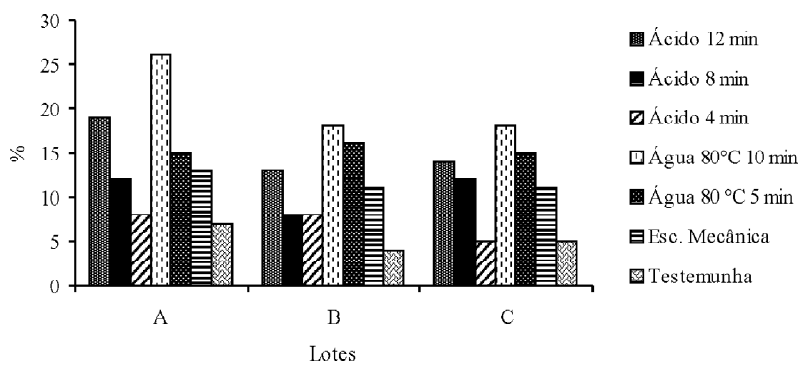

Figura 2 - Porcentagem média de sementes mortas de três lotes de sucupira-preta obtidas no teste de germinação, para os diferentes tratamentos para a superação da dormência. UFLA, Lavras, MG, 2006.

Tabela 3 - Porcentagem de germinação e índice de velocidade de germinação (IVG) de três lotes de sementes de sucupira-preta submetidas a diferentes tratamentos para a quebra da dormência. UFLA, Lavras, MG, 2006.

\begin{tabular}{ccc}
\hline Lotes & \% Germinação & IVG \\
\hline Lote A & $69 \mathrm{~A}$ & $1,59 \mathrm{~A}$ \\
Lote B & $56 \mathrm{~B}$ & $0,50 \mathrm{~B}$ \\
Lote C & $57 \mathrm{~B}$ & $0,76 \mathrm{~B}$ \\
\hline
\end{tabular}

Médias seguidas pela mesma letra na coluna não diferem entre si, pelo teste de Tukey, a 5\% de probabilidade.

Foi observado que as sementes do lote A germinaram em maior porcentagem e maior velocidade que as sementes dos lotes B e C. Esse comportamento pode ser explicado pelo fato das sementes do lote A terem uma maior idade em relação às dos demais lotes. Segundo Marcos Filho (2005), a intensidade de dormência das sementes geralmente tem relação inversamente proporcional à sua idade, independente da sua causa, sendo que a tendência normal é a gradativa superação da mesma à medida que a semente envelhece.

\section{CONCLUSÕES}

Os tratamentos das sementes de sucupira-preta com imersão em ácido sulfúrico por 4, 8 e 12 minutos são eficientes para a superação da dormência.

\section{REFERÊNCIAS BIBLIOGRÁFICAS}

ALLEN, P. S.; MEYER, S. E. Ecological aspects of seed dormancy loss. Seed Science Research, Wallingford, v. 8, n. 2, p. 183-191, June 1998. 
ALVES, M. C. S.; MEDEIROS-FILHO, S.; ANDRADENETO, M.; TEÓFILO, E. M. Superação da dormência em sementes de Bauhinia monandra Britt. e Bauhinia ungulata L. - Caesalpinoideae. Revista Brasileira de Sementes, Brasília, v. 22, n. 2, p. 139-144, 2000.

ANDRADE, A. C. S.; LOUREIRO, B. M.; SOUZA, A. D. de O.; RAMOS, F. N. Quebra de dormência de sementes de sucupira-preta. Pesquisa Agropecuária Brasileira Brasília, v. 32, n. 5, p. 465-469, maio 1997.

BANZATTO, D. A.; KRONKA, S. N. Experimentação agrícola. 3. ed. Jaboticabal: FUNEP, 1995. 247 p.

BARBOSA, A. P.; SAMPAIO, P. de T. B.; CAMPOS, M. A. A.; VARELA, V. P.; GONÇALVES, C. de Q. B.; IIDA, S. Tecnologia alternativa para a quebra de dormência das sementes de pau-de-balsa (Ochroma lagopus Sw. , Bombacaceae). Acta Amazônica, Manaus, v. 34, n. 1, p. 107-110, 2004.

BEWLEY, J. D.; BLACK, M. Seeds: physiology of development and germination. 2. ed. New York: Plenum, 1994. $445 \mathrm{p}$.

BRANDÃO, M.; FERREIRA, P. B. D. Flora apícola do cerrado. Informe Agropecuário, Belo Horizonte, v. 15, n. 168, p. 4-8, 1991.

BRASIL. Ministério da Agricultura e Reforma Agrária. Regras para análises de sementes. Brasília, DF: SNDA/ DNDV/CLAV, 1992. $365 \mathrm{p}$.

BURG, W. J. van der; AARTSE, J. W.; ZWOL, R. A. van; JALINK, H.; BINO, R. J. Predicting tomato seedling morphology by X-ray analysis of seeds. Journal American Society for Horticultural Science, Alexandria, v. 119, n. 2, p. 258-263, Mar. 1994.

CARVALHO, N. M.; NAKAGAWA, J. Sementes: ciência, tecnologia e produção. Jaboticabal: FUNEP, 2000. 588 p.

FERREIRA, D. F. SISVAR 4. 6 - Sistema de análises estatísticas. Lavras: UFLA, 2003.

HERMANSEN, L. A.; DUYEA, M. L.; WHITE, T. L. Variability in seed coat dormancy in Dimorphandra mollis. Seed Science and Technology, Zurich, v. 28, n. 3, p. 567580, 2000.
LIMA JÚNIOR, E. de C. Germinação, armazenamento de sementes e fisio-anatomia de plantas jovens de Cupania vernalis camb. 2004. 115 p. Dissertação (Mestrado em Fisiologia Vegetal) - Universidade Federal de Lavras, Lavras, 2004.

LOPES, J. C.; CAPUCHO, M. T.; KROHLING, B.; ZANOTTI, P. Germinação de sementes de espécies florestais de Caesalpinea férrea Mart. Ex Tul. Var. leiostachya Benth., Cássia grandis L. e Samanea saman Merrill, após tratamento para superar a dormência. Revista Brasileira de Sementes, Brasília, v. 20, n. 1, p. 80-86, 1998.

LORENZI, H. Árvores brasileiras: manual de identificação e cultivo de plantas arbóreas nativas no Brasil. Nova Odessa: Plantarum, 1992. 368 p.

McDONALD, M. B.; COPELAND, L. O. Seed production: principles and practices. New Jersey: Chapmam \& Hall, 1997. $749 \mathrm{p}$

MAGUIRRE, J. D. Speed of germination aid in selection and evaluation for seedling and vigour. Crop Science, Madison, v. 2, n. 2, p. 176-177, Mar./Apr. 1962.

MARCOS FILHO, J. Dormência de sementes. In:

Fisiologia de sementes de plantas cultivadas. Piracicaba: FEALQ, 2005. p. 253-289.

MARTINS-ORDER, M. P.; BORGES, R. Z.; BASTOS JÚNIOR, N. Fotoperiodismo e quebra de dormência em sementes de Acácia negra (Acácia mearnsii De Wild.). Ciência Florestal, Santa Maria, v. 9, n. 1, p. 71-77, jun. 1999.

MAYER, A. M.; POLJAKOFF-MAYBER, A. The germination of seeds. Oxford: Pergamon, 1989. $270 \mathrm{p}$.

MOUSSA, H.; MARGOLIS, H. A.; DUBÉ, P. A.; ODONGO, J. Factores affecting the germination of doum palm (Hyphaene thebaica Mart.) seeds from the semi-arid of Nger, West Africa. Forest Ecology and Management, Amsterdam, v. 104, n. 1/3, p. 27-34, May 1998.

OLIVEIRA, L. M. de. Avaliação da qualidade de sementes de canafístula (Peltophorum dubium (Sprengel) Taubert) pelos testes de germinação, tetrazólio e raios X. 2000. 111 p. Dissertação (Mestrado em Engenharia Florestal) Universidade Federal de Lavras, Lavras, 2000. 
SAMPAIO, L. S. de V.; PEIXOTO, C. P.; PEIXOTO, M. de F. da S. P.; COSTA, J. A.; GARRIDO, M. da S.; MENDES, L. $\mathrm{N}$. Ácido sulfúrico na superação da dormência de sementes de sucupira preta (Bowdichia virgilioides Kunth. Fabaceae). Revista Brasileira de Sementes, Brasília, v. 23, n. 1, p. 184-190, 2001.

SCHATRAL, A.; FOX, J. E. D. Quality and viabilityof seeds in the genus Hibbertia. Seed Science and Technology, Zurich, v. 22, n. 2, p. 273-284, 1994.
SMIDERLE, O. J.; SOUSA, R. de C. P. de. Dormência em sementes de paricarana (Bowdichia virgilioides Kunth Fabaceae-Papilionidae). Revista Brasileira de Sementes, Brasília, v. 25, n. 2, p. 48-52, 2003.

TELES, M. M.; ALVES, A. A.; OLIVEIRA, J. C. G.; BEZERRA, A. M. E. Métodos para quebra da dormência em sementes de leucena (Leucaena leucephala (Lam.) de Wit). Revista Brasileira de Zootecnia, Viçosa, v. 29, n. 2, p. 387-391, 2000. 